\title{
A Proposed Quantitative Conceptual Model for the Assessment of Patient Clinical Outcome
}

\author{
Mou'ath Hourani \\ Software Engineering Department, Faculty of Information Technology \\ Al-Ahliyya Amman University \\ Amman, Jordan
}

\begin{abstract}
The assessment of patient clinical outcome focuses on measuring various aspects of the patient's health status after medical treatments and interventions. Patient clinical outcome assessment is a major concern in the clinical field as the current measures are not well developed and, as a result, they may be used without sufficient understanding of their characteristics. This issue retards the development in the clinical field. This paper proposes a general pure quantitative conceptual model for the assessment of patient clinical outcome. The proposed model contains five WHO's International Classification of Functioning, Disability, and Health (ICF) measurable components: body functions impairment, clinical elegancy distortion, pain, death, and shortening of life expectancy. Total patient clinical outcome is measured by summing the five WHO components. Five validity types are used to validate the proposed model: content, construct, criterion, descriptive, and predictive validities.
\end{abstract}

Keywords-quantitative; conceptual model; assessment; patient clinical outcome

\section{INTRODUCTION}

The assessment of patient clinical outcome is an endpoint health care patient assessment. It is a measuring criteria that focuses on measuring various aspects of the patient's health status after medical treatments and interventions. Outcome assessments monitor and evaluate the quality of patient care by recording clinical outcomes resultant from treatment programs and interventions to observe their effectiveness [1,2].

Recently, the assessment of clinical outcome in health care has been emphasized, in which the effectiveness of care is used to be determined based on purely clinician-centered outcomes to be based on more patient-centered outcomes. Patientcentered outcomes assess the patient's experiences and perceptions of his/her health status. Patient-oriented evidence may be obtained via patient self-report scales that collect a broad range of data that are significant to the patient to measure functional limitations and disability. The use of selfreport scales facilitates the assessment of the net effects of both the health care services on the patient's health-related quality of life (HRQOL) and the condition on the patient. According to the means in which the data are gathered, clinical outcomes measures are classified as patient-based outcomes or clinicianbased outcomes $[1,3,4]$.

Patient-based outcomes provided by the patient via selfreport questionnaires or surveys to identify his/her perspective regarding impairments, function, health, and HRQOL. In general, patients have concerns about the effect on their lifestyle due to their condition, including the capability to accomplish common activities such as dressing, attending events, joining in social occasions, and playing sports. The assessment tools of patient self-report outcomes, that capture patient's experiences and perceptions, are the best to evaluate variables such as disability, societal limitations, and quality of life. Patient self-report measures can be used during any point of the patient care to evaluate the status of a patient and to examine changes in the patient status which resulted from treatment of a medical condition. Patient-based outcomes cover up a broad range of health status factors, including symptoms, global judgments of health, physical function, cognitive functioning, psychological, personal constructs, role activities, and sensitivity to care $[1,3,5]$

Clinician-based outcomes are measures that clinicians do, on the patient's response to a treatment intervention, to stress the assessment of illness and impairment. Even though the clinician-based outcomes assessment is needed to assess the illness and the impairment, it can be misinterpreted and improperly used to deduce functional status. Some clinicianbased measures assess functional limitations as patient goals should be directed toward enhancing function and disability rather than overcoming impairments. Such measures of functional limitations can then be used to direct treatment to improve activities that are difficult to be performed by the patient and are most important to the patient. Besides, thirdparty payers are acquiring an enhancement evidence of the patient's functional outcomes after a treatment program. In addition, self-report outcome tools are the best method to find out the disease effect on the patient's capability to carry out activities on a daily basis and to complete wanted or required roles and responsibilities.[1, 3, 6].

The research of clinical outcomes is the basis for evidencebased practice, that has set the standard for modern health care practice, in which it provides the finest research evidence that facilitates clinical decisions. Particularly, the most significant measures in assessing outcome are the patient-based outcome measures due to the importance of the patient's perception of health status and change in health status. High-quality evidence to verify the effectiveness of interventions can be derived from studies of clinical outcomes. Besides, patient-centered data can be obtained from studies of clinical outcomes that integrate patient-based outcomes. For example, there are two major reasons to justify the importance of clinical outcomes assessment and research studies of clinical outcomes within the athletic training profession. First, a clinical outcomes 
assessment practice and research can present necessary knowledge to athletic trainers for providing best possible patient care. Second, the integration of clinical outcomes measures will allow the assessment of what is important to the patient and to provide patient-centered health care that concentrates on improving patients' HRQOL. Thus, the clinical outcomes assessment tools can be used to help in enhancing patient care by offering patient-oriented evidence for clinicians concerning the effectiveness of their interventions [1].

A number of clinical outcome assessment methods in some clinical fields have been employed without sufficient understanding of their characteristics [7]. This deficient in understanding the characteristics of outcome assessment methods together with the lack of high-quality tools for outcome measurement of illness manifestations restrain the development of therapy. Novel and enhanced methods of assessing the patient clinical outcome can accelerate the process of therapy development [2]. Accordingly, this paper is proposing a quantitative conceptual model for the assessment of patient clinical outcome. The proposed model contains five WHO's International Classification of Functioning, Disability, and Health (ICF) components measurable components: body functions impairment, clinical elegancy distortion, pain, death, and shortening of life expectancy. Total patient clinical outcome is measured by summing the five WHO components. Five validity types are used to validate the proposed model: content, construct, criterion, descriptive, and predictive validities. The remainder of this paper is organized as follows. Section 2 presents the components of the proposed model. Section 3 discusses the validation of the proposed model. In Section 4, we conclude this work and outline potential research directions

\section{EASE OF USE The PROPOSED Patient ClinicAL OUTCOME ASSESSMENT MODEL}

\section{A. General Definitions of Terms in the Proposed Model}

- Harm: it includes any damage in the body function or structure including disease, injury, suffering and death $[8,9]$.

- Tolerable risk: it is the accepted risk that can be managed. [8].

- Causality assessment: it is concerned with the probability of adverse effect arise from using medicine. [10].

- Strength of clinical evidence: it is concerned with evidence quality [11].

- Patient characteristics: it the related attributes under focus [8].

B. The Mathematical Equations of Components of the Proposed Model

1) The Body Function Impairments Mathematical Equation

According to the WHO classification, there are eleven body functions that are used to calculate the multiple body function impairments score for (uncertain) diseases and adverse events
[12]. The following formula us used to calculate the body impairments score:

$\mathrm{BFI}_{\mathrm{S}}=\sum_{\mathrm{BF}=1}^{\mathrm{N}} \mathrm{IMPR}_{\mathrm{BF}} \times \mathrm{D}_{\mathrm{BF}} \times \mathrm{IR}_{\mathrm{BF}} \times \mathrm{OP}_{\mathrm{BF}} \times \mathrm{CR}_{\mathrm{BF}} \times \mathrm{SR}_{\mathrm{BF}}$

Where:

$\mathrm{BFI}_{\mathrm{S}}$ : (Uncertain) total body function impairments score.

$\mathrm{IMPR}_{\mathrm{BF}}$ : Severity ratio of body function impairment.

$\mathrm{D}_{\mathrm{BF}}$ : Duration of body function impairment.

$\mathrm{IR}_{\mathrm{BF}}$ : Intolerability ratio of body function impairment.

$\mathrm{OP}_{\mathrm{BF}}$ : Occurrence probability of body function impairment.

$\mathrm{CR}_{\mathrm{BF}}$ : Causality ratio of body function impairment.

$\mathrm{SR}_{\mathrm{BF}}$ : Strength of clinical evidence ratio of body function impairment.

BF: Body function impairment.

N: No. of body function impairment.

2) The Clinical Elegancy Distortions Mathematical Equation

Clinical elegancy represents the elegant components of the human body, which could be affected by disease or adverse event, and handled in the clinical setting. Clinical elegancy has mainly the following components: Physical appearance change, Undesired odor, Undesired taste, and Undesired audible. The following formula us used to calculate the multiple body size distortions score:

$$
\mathrm{BSD}_{\mathrm{S}}=\sum_{\mathrm{BS}=1}^{\mathrm{M}}\left(\frac{\left|\mathrm{BSNS}_{\mathrm{P}}-\mathrm{BSDS}_{\mathrm{P}}\right|}{\left|\mathrm{BSNS}_{\mathrm{S}}-\mathrm{BSDS}_{\mathrm{S}}\right|}\right) \underset{\mathrm{BS}}{ } \times \mathrm{D}_{\mathrm{BS}} \times \mathrm{IR}_{\mathrm{BS}} \times \mathrm{OP}_{\mathrm{BS}} \times \mathrm{CR}_{\mathrm{BS}} \times \mathrm{SR}_{\mathrm{BS}}
$$

Where:

$\mathrm{BSD}_{\mathrm{S}}$ : (Uncertain) total body size distortions score.

$\mathrm{BSNS}_{\mathrm{P}}$ : Body size at normal state for patient.

BSDS$_{\mathrm{P}}$ : Body size at distorted state for patient.

$\mathrm{BSNS}_{\mathrm{S}}$ : Body size at normal state for the most severe clinical body size distortion case.

BSDS $_{5}$ : Body size at distorted state for the most severe clinical body size distortion case.

$\mathrm{D}_{\mathrm{BS}}$ : Duration of body size distortion.

$\mathrm{IR}_{\mathrm{BS}}$ : Intolerability ratio of body size distortion.

$\mathrm{OP}_{\mathrm{BS}}$ : Occurrence probability of body size distortion.

$\mathrm{CR}_{\mathrm{BS}}$ : Causality ratio of body size distortion.

$\mathrm{SR}_{\mathrm{BS}}$ : Strength of clinical evidence ratio of body size distortion.

BS: Body size distortion.

M: No. of body size distortions.

The following formula is used to calculate the multiple skin disclorations score: 
$\mathrm{SDD}_{S}=\sum_{\mathrm{SD}=1}^{\mathrm{Q}}\left(\frac{\mathrm{DI}_{\mathrm{P}} \times \mathrm{BA}_{\mathrm{P}}}{\mathrm{DI}_{\mathrm{S}} \times \mathrm{BA}_{\mathrm{S}}}\right) \times \mathrm{SD}_{\mathrm{SD}} \times \mathrm{IR}_{\mathrm{SD}} \times \mathrm{OP}_{\mathrm{SD}} \times \mathrm{CR}_{\mathrm{SD}} \times \mathrm{SR}_{\mathrm{SD}}$

Where:

$\mathrm{SDD}_{\mathrm{S}}$ : (Uncertain) total skin discoloration distortions score.

$\mathrm{DI}_{\mathrm{P}}$ : Skin discoloration intensity for patient.

$\mathrm{BA}_{\mathrm{P}}$ : Body area affected with discoloration for patient.

$\mathrm{DI}_{\mathrm{S}}$ : Skin discoloration intensity for the most severe clinical skin discoloration case.

$\mathrm{BA}_{\mathrm{S}}$ : Body area affected with discoloration for the most severe clinical skin discoloration case.

$\mathrm{D}_{\mathrm{SD}}$ : Duration of skin discoloration distortion.

$\mathrm{IR}_{\mathrm{SD}}$ : Intolerability ratio of skin discoloration distortion.

$\mathrm{OP}_{\mathrm{SD}}$ : Occurrence probability of skin discoloration distortion.

$\mathrm{CR}_{\mathrm{SD}}$ : Causality ratio of skin discoloration distortion.

$\mathrm{SR}_{\mathrm{SD}}$ : Strength of clinical evidence ratio of skin discoloration distortion.

SD: Skin discoloration distortion.

Q: No. of skin discoloration distortions.

The following formula is used to calculate the multiple skin hardness distortions score:

$\mathrm{SHD}_{S}=\sum_{\mathrm{SH}=1}^{\mathrm{R}}\left(\frac{\mathrm{HD}_{\mathrm{P}} \times \mathrm{BA}_{\mathrm{P}}}{\mathrm{HD}_{\mathrm{S}} \times \mathrm{BA}_{\mathrm{S}}}\right) \mathrm{SH}_{\mathrm{SH}} \times \mathrm{D}_{\mathrm{SH}_{\mathrm{SH}}} \times \mathrm{OP}_{\mathrm{SH}} \times \mathrm{CR}_{\mathrm{SH}} \times \mathrm{SR}_{\mathrm{SH}}$

Where:

$\mathrm{SHD}_{\mathrm{S}}$ : (Uncertain) total skin hardness distortions score.

$\mathrm{HD}_{\mathrm{P}}$ : Degree of skin hardness for patient.

$\mathrm{BA}_{\mathrm{P}}$ : Body area affected with hardness for patient.

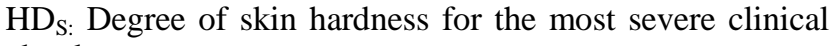
skin hardness case.

$\mathrm{BA}_{\mathrm{S}}$ : Body area affected with hardness for the most severe clinical skin hardness case.

$\mathrm{D}_{\mathrm{SH}}$ : Duration of skin hardness distortion.

$\mathrm{IR}_{\mathrm{SH}}$ : Intolerability ratio of skin hardness distortion.

$\mathrm{OP}_{\mathrm{SH}}$ : Occurrence probability of skin hardness distortion.

$\mathrm{CR}_{\mathrm{SH}}$ : Causality ratio of skin hardness distortion.

$\mathrm{SR}_{\mathrm{SH}}$ : Strength of clinical evidence ratio of skin hardness distortion.

SH: Skin hardness distortion.

R: No. of skin hardness distortions.

The following formula is used to calculate the multiple undesired odor distortions score:
$\mathrm{UOD}_{\mathrm{S}}=\sum_{\mathrm{UO}=1}^{\mathrm{T}}\left(\frac{\mathrm{UOS}_{\mathrm{P}}}{\mathrm{UOS}_{\mathrm{S}}}\right) \mathrm{UO} \times \mathrm{D}_{\mathrm{UO}} \times \mathrm{IR}_{\mathrm{UO}} \times \mathrm{OP}_{\mathrm{UO}} \times \mathrm{CR}_{\mathrm{UO}} \times \mathrm{SR}_{\mathrm{UO}}$

Where:

$\mathrm{UOD}_{\mathrm{S}}$ : (Uncertain) total undesired odor distortions score.

$\mathrm{UOS}_{\mathrm{P}}$ : Severity of undesired odor for patient.

$\mathrm{UOS}_{\mathrm{S}}$ : Severity of undesired odor for most severe clinical undesired odor case.

$\mathrm{D}_{\mathrm{UO}}$ : Duration of undesired odor.

$\mathrm{IR}_{\mathrm{UO}}$ : Intolerability ratio of undesired odor.

$\mathrm{OP}_{\mathrm{UO}}$ : Occurrence probability of undesired odor.

$\mathrm{CR}_{\mathrm{UO}}$ : Causality ratio of undesired odor.

$\mathrm{SR}_{\mathrm{UO}}$ : Strength of clinical evidence ratio of undesired odor.

UO: Undesired odor distortion.

T: No. of undesired odor distortions.

The following formula is used to calculate the multiple undesired taste distortions score:

$\mathrm{UTD}_{S}=\sum_{\mathrm{UT}=1}^{\mathrm{U}}\left(\frac{\mathrm{UTS}_{\mathrm{P}}}{\mathrm{UTS}_{\mathrm{S}}}\right) \mathrm{UT} \times \mathrm{D}_{\mathrm{UT}} \times \mathrm{IR}_{\mathrm{UT}} \times \mathrm{OP}_{\mathrm{UT}} \times \mathrm{CR}_{\mathrm{UT}} \times \mathrm{SR}_{\mathrm{UT}}$

Where:

$\mathrm{UTD}_{\mathrm{S}}$ : (Uncertain) total undesired taste distortions score.

$\mathrm{UTS}_{\mathrm{P}}$ : Severity of undesired taste for patient.

UTS $_{\mathrm{S}}$ : Severity of undesired taste for most severe clinical undesired taste case.

$\mathrm{D}_{\mathrm{UT}}$ : Duration of undesired taste.

$\mathrm{IR}_{\mathrm{UT}}$ : Intolerability ratio of undesired taste.

$\mathrm{OP}_{\mathrm{UT}}$ : Occurrence probability of undesired taste.

$\mathrm{CR}_{\mathrm{UT}}$ : Causality ratio of undesired taste.

$\mathrm{SR}_{\mathrm{UT}}$ : Strength of clinical evidence ratio of undesired taste.

UT: Undesired taste distortion.

U: No. of undesired taste distortions.

The following formula is used to calculate the multiple undesired audible distortions score:

$\mathrm{UAD}_{S}=\sum_{\mathrm{UA}=1}^{\mathrm{v}}\left(\frac{\mathrm{UAS}_{\mathrm{P}}}{\mathrm{UAS}_{\mathrm{S}}}\right) \mathrm{UA} \times \mathrm{D}_{\mathrm{UA}} \times \mathrm{IR}_{\mathrm{UA}} \times \mathrm{OP}_{\mathrm{UA}} \times \mathrm{CR}_{\mathrm{UA}} \times \mathrm{SR}_{\mathrm{UA}}$

Where:

$\mathrm{UAD}_{\mathrm{S}}$ : (Uncertain) total undesired audible distortions score.

$\mathrm{UAS}_{\mathrm{P}}$ : Severity of undesired audible for patient.

$\mathrm{UAS}_{\mathrm{S}}$ : Severity of undesired audible for most severe clinical undesired audible case. 
$\mathrm{D}_{\mathrm{UA}}$ : Duration of undesired audible.

$\mathrm{IR}_{\mathrm{UA}}$ : Intolerability ratio of undesired audible.

$\mathrm{OP}_{\mathrm{UA}}$ : Occurrence probability of undesired audible.

$\mathrm{CR}_{\mathrm{UA}}$ : Causality ratio of undesired audible.

$\mathrm{SR}_{\mathrm{UA}}$ : Strength of clinical evidence ratio of undesired audible.

UA: Undesired audible distortion.

$\mathrm{V}$ : No. of undesired audible distortions.

Finally, the following formula is used to calculate the Clinical elegancy distortions score:

$\mathrm{CED}_{\mathrm{s}}=\mathrm{BSD}_{\mathrm{s}}+\mathrm{SDD}_{\mathrm{s}}+\mathrm{SHD}_{\mathrm{s}}+\mathrm{UOD}_{\mathrm{s}}+\mathrm{UTD}_{\mathrm{s}}+\mathrm{UAD}_{\mathrm{s}}$

Where:

$\mathrm{CED}_{\mathrm{S}}$ : (Uncertain) total clinical elegancy distortions score.

BSD $_{\mathrm{S}}$ : (Uncertain) total body size distortions score.

$\mathrm{SDD}_{\mathrm{S}}$ : (Uncertain) total skin discoloration distortions score.

SHD : (Uncertain) total skin hardness distortions score.

$\mathrm{UOD}_{\mathrm{S}}$ : (Uncertain) total undesired odor distortions score.

$\mathrm{UTD}_{\mathrm{S}}$ : (Uncertain) total undesired taste distortions score.

$\mathrm{UAD}_{\mathrm{S}}$ : (Uncertain) total undesired audible distortions score.

3) Physical and Non Physical Pains Mathematical Equation

Pain is defined as an extremely unlikable physical feeling due to illness or injury. Pain is associated by tissue damage and emotional experience. [13]. Depression, anger, frustration, fear, and anxiety feelings are examples of emotional pain [14]. The following formula is used to calculate the multiple pain types score:

$$
\mathrm{PT}_{S}=\sum_{\mathrm{PT}=1}^{\mathrm{W}}\left(\frac{\mathrm{PTI}_{\mathrm{P}}}{\mathrm{PTI}_{\mathrm{S}}}\right) \underset{\mathrm{PT}}{ } \times \mathrm{D}_{\mathrm{PT}} \times \mathrm{IR}_{\mathrm{PT}} \times \mathrm{OP}_{\mathrm{PT}} \times \mathrm{CR}_{\mathrm{PT}} \times \mathrm{SR}_{\mathrm{PT}}
$$

Where:

$\mathrm{PT}_{\mathrm{S}}$ : (Uncertain) total pain types score.

PTI : Pain type intensity or severity for patient.

PTI $_{S}$ : Pain type intensity or severity for the most severe clinical case of the same pain type.

$\mathrm{D}_{\mathrm{PT}}$ : Duration of pain type.

$\mathrm{IR}_{\mathrm{PT}}$ : Intolerability ratio of pain type.

$\mathrm{OP}_{\mathrm{PT}}$ : Occurrence probability of pain type.

$\mathrm{CR}_{\mathrm{PT}}$ : Causality ratio of pain type.

$\mathrm{SR}_{\mathrm{PT}}$ : Strength of clinical evidence ratio of pain type.

PT: Pain type.

W: No. of pain types.
Pain severity can be quanitifed and scale standardized to enable comparability between differnet cases [15].

\section{4) Death Mathematical Equation}

Death is a body functionalities and all clinical elegancy component distortion. Death is associated with the presence of all extreme pain types, therefore, the sum of the highest clinical values for body function impairments, clinical elegancy distortions, and different pain types is used to calculate the death clinical score. Constant value is added to the first three components model to differentiate severity of different clinical death cases. The following formula is used calculate death clinical score:

$\mathrm{DCS}=\left(\mathrm{HBFI}_{\mathrm{S}}+\mathrm{HCED}_{\mathrm{S}}+\mathrm{HPT}_{\mathrm{S}}+\mathrm{MCV}\right) \times \mathrm{OP}_{\mathrm{D}} \times \mathrm{CR}_{\mathrm{D}} \times \mathrm{SR}_{\mathrm{D}}$

Where:

DCS: (Uncertain) death clinical score.

$\mathrm{HBFI}_{\mathrm{S}}$ : Highest clinical value recorded for body function impairments.

$\mathrm{HCED}_{\mathrm{S}}$ : Highest clinical value recorded for clinical elegancy distortions.

$\mathrm{HPT}_{\mathrm{S}}$ : Highest clinical value recorded for different pain types.

MCV: Smallest clinical value recorded for body function impairments, clinical elegancy distortions, or different pain types.

$\mathrm{OP}_{\mathrm{D}}$ : Occurrence probability of death.

$\mathrm{CR}_{\mathrm{D}}$ : Causality ratio of death.

$\mathrm{SR}_{\mathrm{D}}$ : Strength of clinical evidence ratio of death.

\section{Total Value of Patient Clinical Outcome Mathematical Equation}

By summing all model components, the following formula is used to calculate the patient clinical outcome:

$$
\mathrm{PCO}=\mathrm{BFI}_{\mathrm{S}}+\mathrm{CED}_{\mathrm{S}}+\mathrm{PT}_{\mathrm{S}}+\mathrm{DCS}
$$

Where:

PCO: Patient clinical outcome.

$\mathrm{BFI}_{\mathrm{S}}$ : (Uncertain) total body function impairments score.

$\mathrm{CED}_{\mathrm{S}}$ : (Uncertain) total clinical elegancy distortions score.

$\mathrm{PT}_{\mathrm{S}}$ : (Uncertain) total pain types score.

DCS: (Uncertain) death clinical score.

\section{The VAlidation OF THE PROPOSED MODEL}

Validity measures the reliability of the results obtained from experiment [16-18]. It also verifies the freedom of results from errors [19]. The proposed model is measured against three types of validity: content, construct, and predictive validities.

- Content validity: it concerns with experiment domain construction. It also signifies the domain clarity, 
completeness and confirmation [17, 20-26]. In our model, the domain criteria that are included for validation are all ICF health items.

- Construct validity: it tests and assesses the logical relationships between related concepts [17, 20, 22]. In our proposed model, the logical relationships between all health dimensions are represented and precisely defined.

- Descriptive validity: it is the expression of proposed decisions in any situations [27]. In our proposed model, the output from the model is verified by explaining and describing the obtained decisions in any clinical environment.

To sum up, there is no standard validity test for the results. Using the described validity test described previously does not certain the obtained results [27-29]. Therefore, before validating the results, a threshold should be established.

\section{CONCLUSIONS}

This paper proposes a general pure quantitative conceptual model for the assessment of patient clinical outcome. The model contains five major measurable components which are mainly based on the WHO's International Classification of Functioning, Disability, and Health (ICF) components. Those components are body functions impairment, clinical elegancy distortion, pain, death, and shortening of life expectancy. Patient clinical outcome is calculated as the summation of model component values for the patient with specific characteristics and status. The proposed model is verified against five types of validity checks: content, construct, criterion, descriptive, and predictive validities. Future study will focus on identifying facilitators and barriers to the successful implementation of the proposed model in clinical practice.

\section{REFERENCES}

[1] T. C. V. McLeod, A. R. Snyder, J. T. Parsons, R. C. Bay, L. A. Michener, and E. L. Sauers, "Using disablement models and clinical outcomes assessment to enable evidence-based athletic training practice, part II: clinical outcomes assessment," Journal of athletic training, vol. 43, pp. 437-445, 2008.

[2] M. K. Walton, J. H. Powers, J. Hobart, D. Patrick, P. Marquis, S. Vamvakas, M. Isaac, E. Molsen, S. Cano, and L. B. Burke, "Clinical Outcome Assessments: Conceptual Foundation-Report of the ISPOR Clinical Outcomes Assessment-Emerging Good Practices for Outcomes Research Task Force," Value in Health, vol. 18, pp. 741-752, 2015.

[3] C. M. Clancy and J. M. Eisenberg, "Outcomes research: measuring the end results of health care," Science, vol. 282, pp. 245-246, 1998.

[4] D. T. Wade, "Outcome measures for clinical rehabilitation trials: impairment, function, quality of life, or value?," American journal of physical medicine \& rehabilitation, vol. 82, pp. S26-S31, 2003.

[5] A. Kirkley and S. Griffin, "Development of disease-specific quality of life measurement tools," Arthroscopy: The Journal of Arthroscopic \& Related Surgery, vol. 19, pp. 1121-1128, 2003.

[6] J. Binkley, "Measurement of functional status, progress and outcome in orthopaedic clinical practice," Orthop Phys Ther Pract, vol. 11, pp. 1421, 1999.

[7] P. I. Spuls, L. L. Lecluse, M.-L. N. Poulsen, J. D. Bos, R. S. Stern, and T. Nijsten, "How Good Are Clinical Severity and Outcome Measures for Psoriasis\&quest;: Quantitative Evaluation in a Systematic Review," Journal of Investigative Dermatology, vol. 130, pp. 933-943, 2010.
[8] WHO, "The conceptual framework for the international classification for patient safety version 1.1: Final technical report," World Health Organization2009.

[9] W. Runciman, "Shared meanings: Preferred terms and definitions for safety and quality concepts," The Medical Journal of Australia, vol. 184, pp. S41-S43, 2006.

[10] K. Holloway, T. Green, E. Carandang, H. Hogerzeil, R. Laing, and D. Lee, Drug and therapeutics committees: A practical guide. France: World Health Organization, 2003.

[11] J. L. Brożek, E. A. Akl, P. Alonso-Coello, D. L. Lang, R. Jaeschke, J. W. Williams, B. Phillips, M. Lelgemann, A. Lethaby, J. Bousquet, G. H. Guyatt, H. J. Schünemann, and G. W. Group, "Grading quality of evidence and strength of recommendations in clinical practice guidelines," Allergy, vol. 64, pp. 669-677, 2009.

[12] WHO, International Classification of Functioning, Disability and Health (ICF) short version. Geneva: World Health Organization, 2001.

[13] IASP, "Pain terms: A list with definitions and notes on usage," Pain, vol. 6, pp. 249-252, 1979.

[14] J. B. Wade, D. D. Price, R. M. Hamer, S. M. Schwartz, and R. P. Hart, "An emotional component analysis of chronic pain," Pain, vol. 40, pp. 303-310, 1990.

[15] R. L. Kane, B. Bershadsky, T. Rockwood, K. Saleh, and N. C. Islam, "Visual Analog Scale pain reporting was standardized," Journal of Clinical Epidemiology, vol. 58, pp. 618-623, 2005.

[16] D. Sornette, A. B. Davis, K. Ide, K. R. Vixie, V. Pisarenko, and J. R. Kamm, "Algorithm for model validation: Theory and applications," Proceedings of the National Academy of Sciences, vol. 104, pp. 65626567, April 17, 2007.

[17] L. Mokkink, C. B. Terwee, D. L. Patrick, J. Alonso, P. W. Stratford, D. L. Knol, L. M. Bouter, and H. C. W. de Vet, "The COSMIN study reached international consensus on taxonomy, terminology, and definitions of measurement properties for health-related patient-reported outcomes," Journal of Clinical Epidemiology, vol. 63, pp. 737-745, 2010.

[18] D. Bryant and N. Fernandes, "Measuring patient outcomes: A primer," Injury, vol. 42, pp. 232-235, 2011.

[19] E. J. Thomas and L. A. Petersen, "Measuring errors and adverse events in health care," Journal of General Internal Medicine, vol. 18, pp. 61-67, 2003.

[20] K. N. Lohr, N. K. Aaronson, J. Alonso, M. Audrey Burnam, D. L. Patrick, E. B. Perrin, and J. S. Roberts, "Evaluating quality-of-life and health status instruments: Development of scientific review criteria," Clinical Therapeutics, vol. 18, pp. 979-992, 1996.

[21] S. J. Coons, S. Rao, D. L. Keininger, and R. D. Hays, "A Comparative review of generic quality-of-life instruments," PharmacoEconomics, vol. 17, pp. 13-35, 2000.

[22] Scientific Advisory Committee of the Medical Outcomes Trust, "Assessing health status and quality-of-life instruments: Attributes and review criteria," Quality of Life Research, vol. 11, pp. 193-205, 2002.

[23] M. Ryan, D. Scott, C. Reeves, A. Bate, E. v. Teijlingen, E. Russell, M. Napper, and C. Robb, "Eliciting public preferences for healthcare: A systematic review of techniques," Health Technology Assessment vol. 5, 2001.

[24] J. H. Duffus, M. Nordberg, and D. M. Templeton, "Glossary of terms used in toxicology, 2nd edition (IUPAC Recommendations 2007)," Pure \& Applied Chemistry, vol. 79, pp. 1153-1344, 2007.

[25] G. H. Guyatt, D. H. Feeny, and D. L. Patrick, "Measuring health-related quality of life," Annals of Internal Medicine, vol. 118, pp. 622-629, April 15, 1993.

[26] A. Y. Chen and A. S. Whigham, "Validation of Health Status Instruments," Journal for Oto - Rhino - Laryngology and Its Related Specialties, vol. 66, pp. 167-172, 2004.

[27] C. McCabe and S. Dixon, "Testing the validity of cost-effectiveness models," PharmacoEconomics, vol. 17, pp. 501-513, 2000.

[28] J. Hay, J. Jackson, B. Luce, J. Avorn, and T. Ashraf, "Panel 2: Methodological issues in conducting pharmacoeconomic evaluationsmodeling studies," Value in Health, vol. 2, pp. 78-81, 1999. 
[29] C. B. Terwee, F. W. Dekker, W. M. Wiersinga, M. F. Prummel, and P. M. M. Bossuyt, "On assessing responsiveness of health-related quality of life instruments: Guidelines for instrument evaluation," Quality of Life Research, vol. 12, pp. 349-362, 2003. 